\title{
Calculation of Wake Power Losses in a Two-Level Array: A Simple Case Study
}

J. C. Barnard

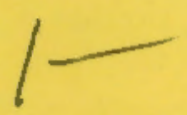

December 1985

Prepared for the U.S. Department of Energy under Contract DE-AC06-76RLO 1830

Pacific Northwest Laboratory Operated for the U.S. Department of Energy by Battelle Memorial Institute 


\title{
DISCLAIMER
}

This report was prepared as an account of work sponsored by an agency of the United States Government. Neither the United States Government nor any agency thereof, nor any of their employees, makes any warranty, express or implied, or assumes any legal liability or responsibility for the accuracy, completeness, or usefulness of any information, apparatus, product, or process disclosed, or represents that its use would not infringe privately owned rights. Reference herein to any specific commercial product, process, or service by trade name, trademark, manufacturer, or otherwise, does not necessarily constitute or imply its endorsement, recommendation, or favoring by the United States Government or any agency thereof. The views and opinions of authors expressed herein do not necessarily state or reflect those of the United States Government or any agency thereof.

\author{
PACIFIC NORTHWEST LABORATORY \\ operated by \\ BATTELLE \\ for the \\ UNITED STATES DEPARTMENT OF ENERGY \\ under Contract DE-AC06-76RLO 1830
}

\begin{tabular}{|c|c|}
\hline \multirow{2}{*}{\multicolumn{2}{|c|}{ Printed in the United States of America }} \\
\hline & \\
\hline \\
\hline \multicolumn{2}{|c|}{$\begin{array}{l}\text { National Technical Information Service } \\
\text { United States Department of Commerce }\end{array}$} \\
\hline 5285 & \\
\hline \multicolumn{2}{|c|}{ Springfield, Virginia 22161} \\
\hline \multirow{2}{*}{\multicolumn{2}{|c|}{$\begin{array}{l}\text { NTIS Price Codes } \\
\text { Microfiche A01 }\end{array}$}} \\
\hline & \\
\hline \multicolumn{2}{|c|}{ Printed Copy } \\
\hline & Price \\
\hline Pages & Codes \\
\hline 001-025 & $\mathrm{A} 02$ \\
\hline 026-050 & $\mathrm{A} 03$ \\
\hline 051-075 & A04 \\
\hline $076-100$ & A05 \\
\hline $101-125$ & 106 \\
\hline $126-150$ & A07 \\
\hline $151-175$ & $A 08$ \\
\hline $176-200$ & $\mathrm{~A} 09$ \\
\hline $201-225$ & A010 \\
\hline 226-250 & A011 \\
\hline $251-275$ & A012 \\
\hline $276-300$ & A013 \\
\hline
\end{tabular}


PNL -5721

UC- 60

CALCULATION OF WAKE POWER LOSSES IN A TWO-LEVEL ARRAY: A SIMPLE CASE STUDY

J. C. Barnard

December 1985

Prepared for the U.S. Department of Energy under Contract DE-ACD6-76RLO 1830

Pacific Northwest Laboratory

Richland, Washington 99352 


\section{SLMMARY}

It is sometimes desirable to increase the power-producing capacity of a wind turbine array. Usually capacity is increased by purchasing additional property and installing more turbines. However, property around an existing array may be unavailable or prohibitively expensive, thereby precluding this option. Another method of adding capacity is to install another array of turbines whose hub height is above the existing array. This method may be an attractive alternative if wake interference is small between the new and existing turbine levels.

This report estimates the wake interference that could be expected in a two-ievel array. Interference is estimated for a typical situation that may be encountered by a wind farm developer. A modified Lissaman array model is used to make the wake interference calculations.

The model calculations show that the wake interference between the two levels is small--at least for the turbine characteristics and turbine layouts considered in this report. (The windwise spacings are about 5.4 and 10.8D for the lower and upper levels of turbines, respectively.) Power losses are about $5 \%$ or less at rated speed. Thus, two-leve? arrays may be a viable way of increasing the generating capacity of existing wind farms. 

CONTENTS

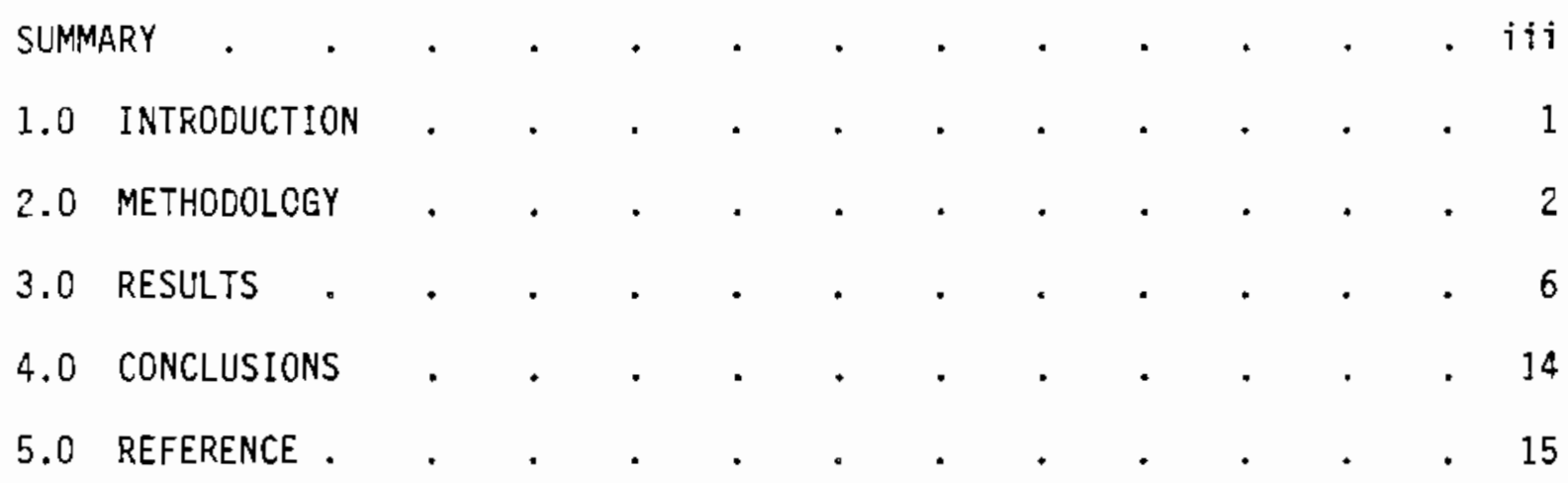

v 


\section{FIGURES}

1. Turbine Layout for Wake Interference Test . . . . . 3

2. Power Loss as a Function of Wind Speed . . . . . . . . . 7

3. Comparison of Average Power Output for Layout A

(turbulence intensity $=3 \%$ ) . . . . . . . . . 8

4. Comparison of Average Power Output for Layout $A$

(turbulence intensity $=8 \%$ ) . . . . . . . . . 8

5. Comparison of Average Power Output for Layout A . . . . . 9 (turbulence intensity $=12 \%$ )

6. Second Turbine Layout for Wake Interference Test . . . . 11

7. Third Turbine Layout for Wake Interference Test • + . . 12

8. Power Loss as a Function of Wind Speed . . . . . . . . 13 


\subsection{INTRODUCTION}

This report addresses a wake interference problem. It is proposed to increase the power-producing capacity of a wind farm by aoding additicna 1 turbines to an existing array of identical turbines. The proposed turbines would be placed within the boundaries of the original array and the hub height of these turbines would be greater than that of the existing turbines. This would create a two-level array and wake interference between the new and existing turbines would occur. However, if this interference proved to be sma11, then an efficient increase in power production could be realized without purchasing additional land. This report is concerned with estimating the wake interference.

The problem of estimating wake interference is attacked through a case study of a particular array. This array is located in relatively flat terrain in the San Gorgonio Pass area of southern California and is composed of comercially available turbines. The array is acted upon by winds that are primarily from the west $\left(270^{\circ}\right)$.

The wake calculations that follow were made using the well-known Lissaman array model (Lissaman 1982). As array power estimates made by this model have never been verified by comparison to actual array power data, it is not yet known how well the model performs. It is important to realize that the results presented in this report are based on an unverified numerical model. 


\subsection{METHODOLOGY}

The first step of this effort was to modify the Lissaman model to handle turbines of different hub heights. This could only be done easily by introducing two assumptions. The first of these is that the wind speed is assumed to be constant with height. This is not a realistic assumption. For the two hub heights considered in this study (60 and $120 \mathrm{ft}$ ), the turbines in the upper level would experience a larger wind speed than those in the lower level. The enhanced power output of the upper level, resulting from the increased wind speed, is not considered in this report.

The second assumption is that all turbines in the array are identical (except for their hub heights). This assumption could only be relaxed by making extensive and time-consuming revisions to the Lissaman code.

When the modification of the code was completed, the model was put through a number of quality assurance checks to assure proper functioning. It passed all checks.

Next the physical layout for the wind turbines was digitized. This layout is shown in Figure 1; the 84 existing turbines with a hub height of $60 \mathrm{ft}$ are shown as circles, and the 42 proposed turbines of $120-\mathrm{ft}$ hub height are indicated by a cross. The layout of smaller turbines is exactly as they are now positioned on a wind farm in San Gorgonio Pass in southern California. For the small-hub-height turbines, the east-west spacing is $350 \mathrm{ft}$ and the north-south spacing is $90 \mathrm{ft}$. The proposed turbines will have an east-west spacing of $700 \mathrm{ft}$ and the same north-south spacing of $90 \mathrm{ft}$. They will be arranged so that along the first and third north-south columns of existing turbines, one large hub-height turbine will be exactly half-way between two of the existing turbines. (This layout will be modified for additional testing as will be described later.) To distinguish between the turbine layouts, the one shown in Figure 1 is designated layout $A$.

Both the new and proposed machines in the array are assumed to be $180-\mathrm{kW}$ turbines. Specifications for these machines are: 


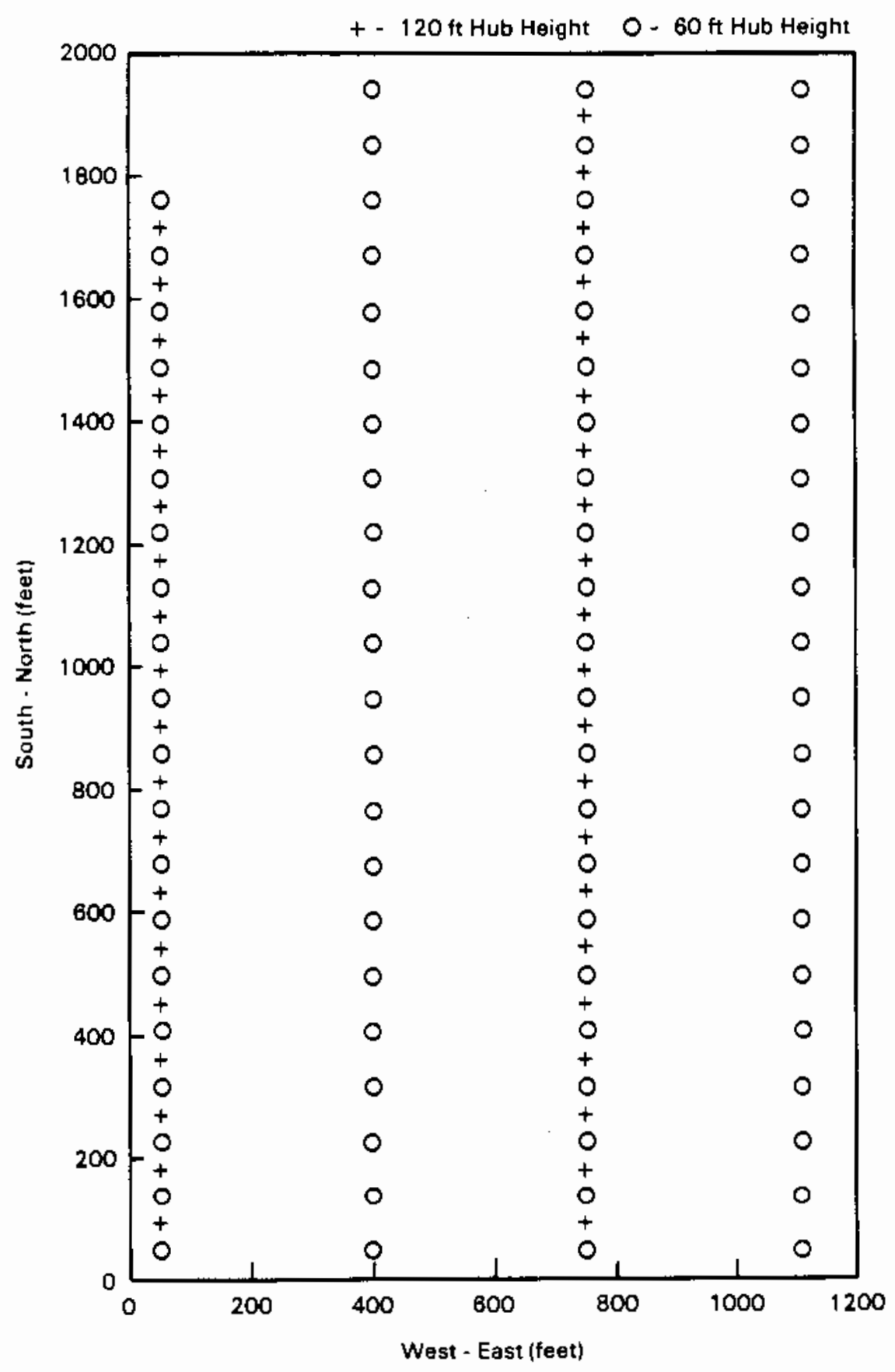

FIGURE 1. Turbine Layout for Wake Interference Test (Layout A) 


$\begin{array}{ll}\text { Rated Power } & 180 \mathrm{kh} \\ \text { Cut-in Speed } & 11 \mathrm{mph} \\ \text { Rated Speed } & 40 \mathrm{mph} \\ \text { Cutout Speed } & 60 \mathrm{mph} \\ \text { Rotor Diameter } & 65 \mathrm{ft} \\ \text { Hub Height } & 60 \mathrm{ft} \mathrm{\&} \mathrm{120} \mathrm{ft} \\ \begin{array}{l}\text { C at Rated Power } \\ \text { Blade Drag Coefficient } \\ \quad \text { (at rated power) }\end{array} & 0.2 \\ \begin{array}{l}\text { Rotor Solidity } \\ \text { Tip Speed Ratio } \\ \text { (at rated power) }\end{array} & 0.14 \\ \end{array}$

These specifications, typical of commercially available turbines, are used as input into the Lissaman model.

To gauge the effect of adding an upper level of turbines, the average power output per turbine of the new array is compared to the average power output of this array if no wake interaction between levels were allowed. This comparison shows the number of kilowatts that are lost (per turbine) as a result of adding an upper level of turbines. The loss is a function of wind speed, wind direction, and transverse turbulence intensity.

Calculation of this power loss is simple. For a given set of the abovementioned meteorological variables, the Lissaman model is exercised for only the lower level of turbines, and the calculated power output is called $\mathrm{P}_{\ell}$. For this calculation the upper level of turbines is assumed to be turned off. Then the lower level is turned off, and the power output, called $P_{u}$, is calculated for the upper level. Finally, both levels are assumed to be operating and the model calculates $P_{b}$, the power sutput of the entire array.

The value $\mathrm{P}_{\mathrm{b}}$ includes both the power losses caused by wakes generated in each level acting upon turbines in the same level, and losses caused by wake interference between levels. The values $P_{\ell}$ and $P_{u}$ only include wake losses in the lower and upper levels, respectively. The value $P_{b}$ is then less than the sum of $P_{\ell}$ and $P_{u}$, and this difference, $P_{\ell}+P_{u}-P_{b}$, is an estimate of the power loss due to wake interference between levels. This is what the 
wind farm developer loses by adding an additional level of turbines. For the results that follow, the power loss (or power output) has been normalized by the total number of turbines in the array, which is 126 . The result is the power loss (or power output) per turbine. 


\subsection{RESULTS}

The power loss has been calculated for a matrix of meteorological conditions that are thought to well represent those found at a wind farm in San Gorgonio Pass. The strong winds at this site are from the west, and the model was run for wind directions from $250^{\circ}$ to $290^{\circ}$ in increments of $5^{\circ}$.

For each wind direction, a transverse turbulence intensity must be specified. (The transverse intensity is that component of the turbulence intensity perpendicular to the wind velocity). Measurements of this parameter close to the site in question are not known to exist, and a range of transverse turbulence intensities was assumed that represents low, medium, and high values of this parameter for flat terrain. These values are $3 \%, 8 \%$, and $12 \%$, respectiveiy.

Finally, for each wind direction and turbulence intensity the model calculates the power output of the array for wind speeds of 0 to $60 \mathrm{mph}$.

Figure 2 shows the power loss per turbine as a function of wind speed for three different transverse turbulence intensities. In this figure the wind direction is assumed to be $270^{\circ}$. (The calculations are quite insensitive to wind direction in the range $250^{\circ}$ to $290^{\circ}$ and results for other wind directions will not be shown.) Figure 2 shows the maximum power loss per turbine to be about $10 \mathrm{~kW}$ at about $40 \mathrm{mph}$. (The power gain around $50 \mathrm{mph}$ for the $3 \%$ turbulence cannot be real. In the Lissaman model, the array efficiency is calculated assuming that all the machines are operating at the rated power coefficient. The resulting efficiency is then extrapolated to predict the performance of the array at other wind speeds. This technique causes some error in array power calculations near the cut-in and rated speeds. For the $3 \%$ turbulence leve?, this error manifests itself by the anomalous power gain and the small spike near the cut-in speed.)

The power loss increases with transverse turbulence intensity. The reason for this is that the power loss due to wake interaction between levels is caused by the vertical growth of wakes from one level into the other level. The growth rate of the wake radius (as a function of downstream distance from 


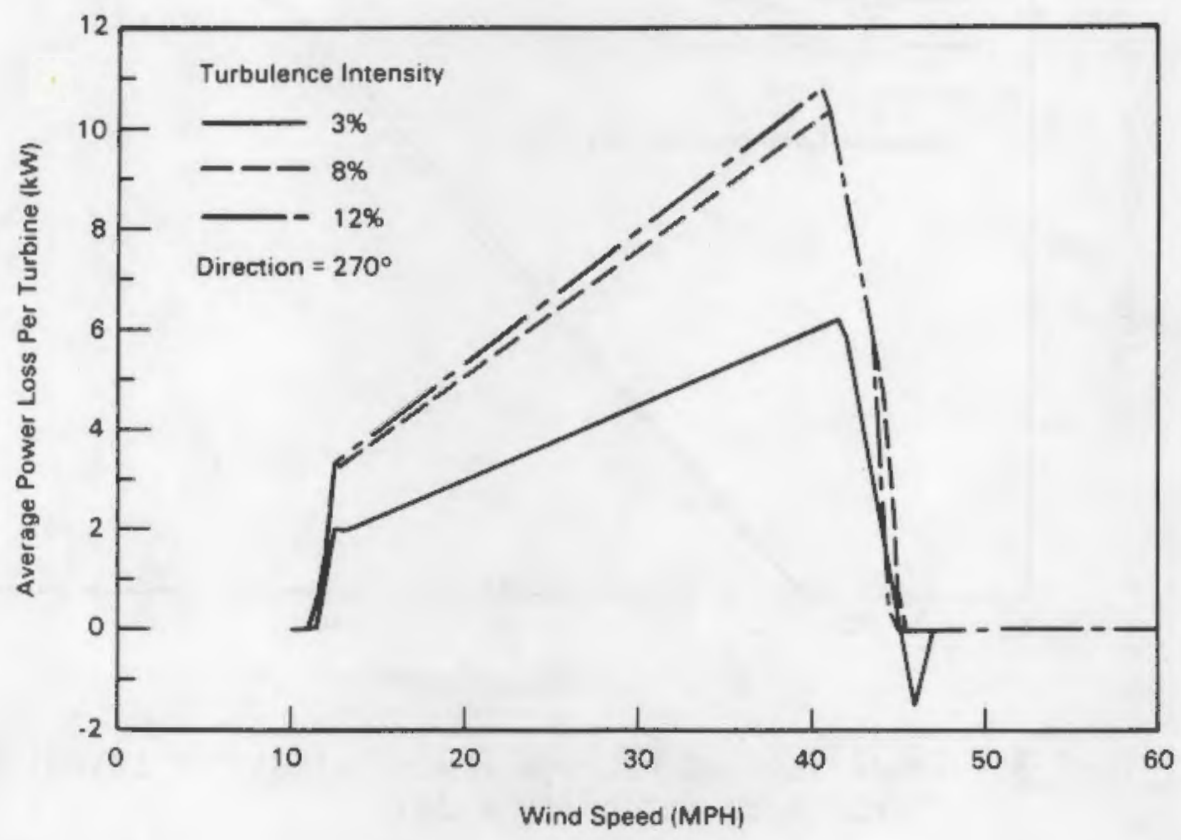

FIGURE 2. Power Loss (per turbine) as a Function of Wind Speed (Layout A)

the turbine) is governed by the transverse turbulence intensity--the greater the turbulence, the larger the growth rate. Higher turbulence levels, therefore, lead to larger wake radii, which in turn cause more wake interference between the vertical levels. This can be termed a "wake edge" effect.

It is useful to compare the power output of the lower and upper arrays $\left(P_{\ell}+P_{u}\right)$ to the output of combined array, $P_{b}$. Figures 3,4 , and 5 show the power output plotted against wind speed at three different levels of the transverse turbulence intensity. When viewed in this manner, the power loss (which is the vertical distance between the solid and dotted lines) is rather small.

It is interesting to note that the power outputs of the lower and upper arrays $\left(P_{\ell}+P_{u}\right)$ and the combined array $\left(P_{b}\right)$ increase with transverse turbulence intensity at any given wind speed below about $50 \mathrm{mph}$. This effect is 


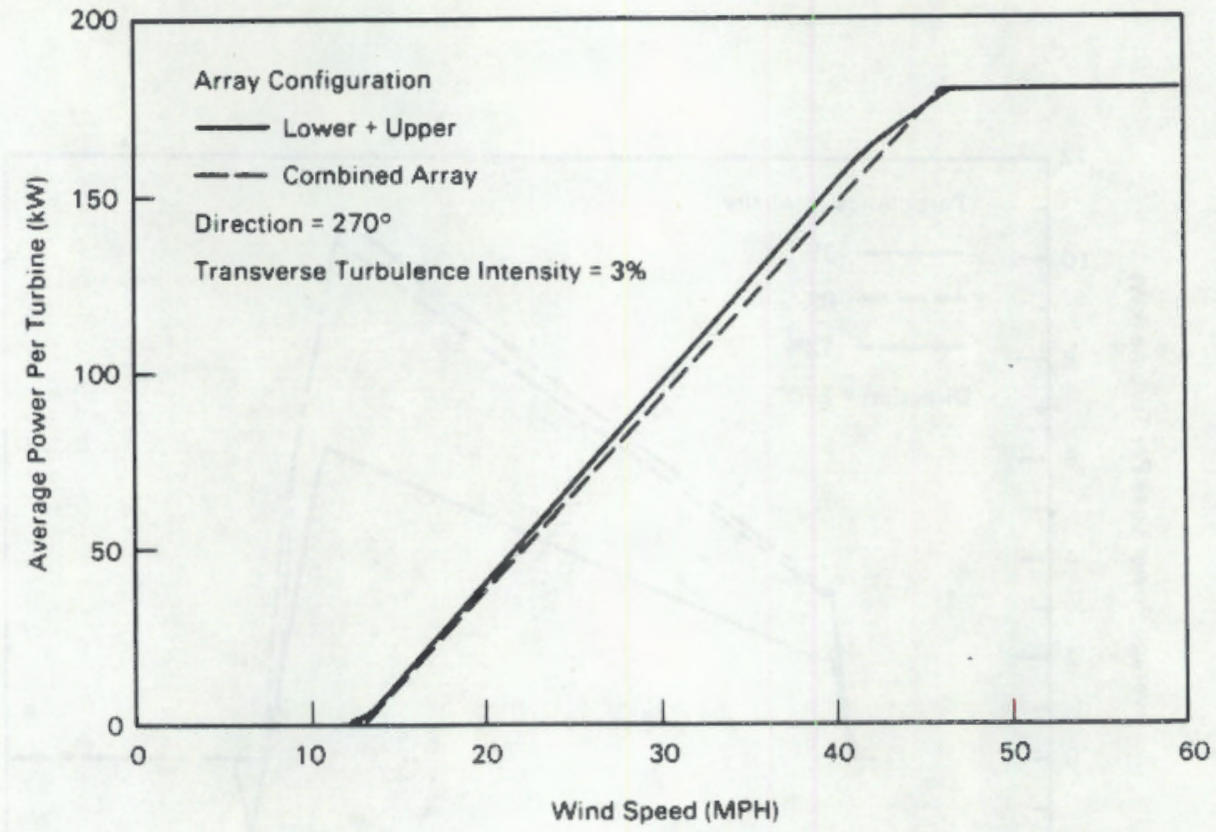

FIGURE 3. Comparison of Average Power Output for Layout A (turbulence intensity $=3 \%$ )

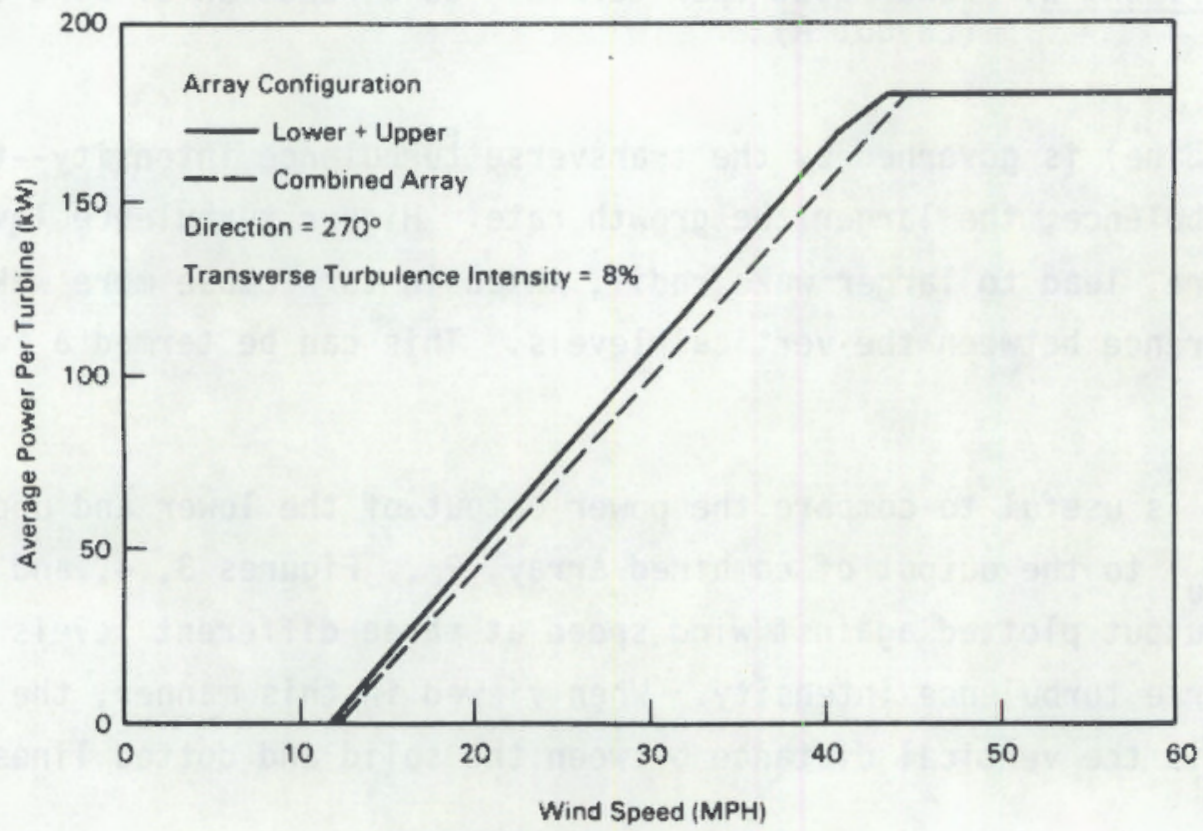

FIGURE 4. Comparison of Average Power Output for Layout A (turbulence intensity $=8 \%$ ) 


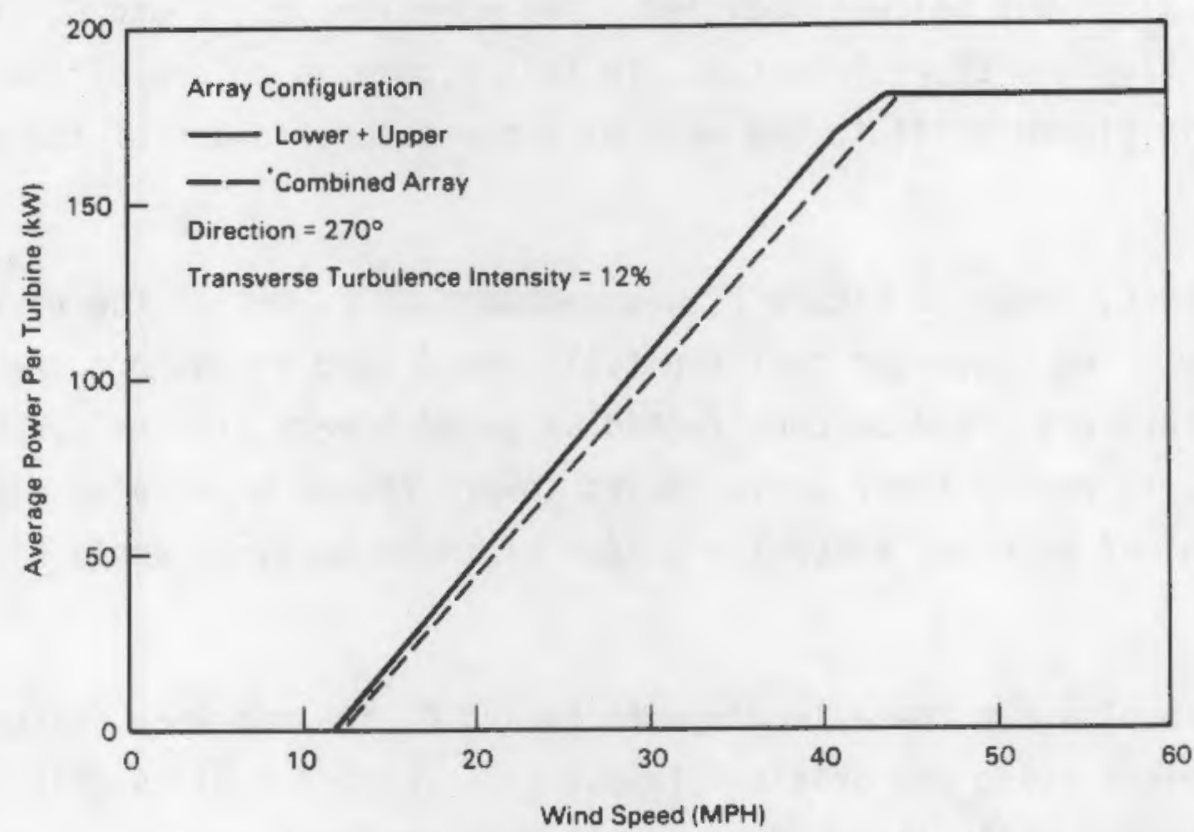

FIGURE 5. Comparison of Average Power Qutput for Layout A (turbulence intensity $=12 \%$ )

usually observed in single-level array calculations. It results from the decrease of the momentum deficit close to the wake centerline as the transverse turbulence intensity increases. In a single-level array, when the turbines are aligned so that one is directly downwind of another (or nearly so), the downwind turbines are affected most strongly by the deficit near the centerline. (The deficit near the wake edge does not impinge upon the downwind rotor.) As the "near centerline" deficit decreases with greater turbulence, the power output of the array becomes larger. This can be called a "wake centerline" effect.

In the two-level array, a greater turbulence increases the wake interference between levels as a result of the wake edge effects. However, this is more than compensated for by the decrease in wake interference within each level of the array that results from the wake centerline effect. Therefore, in this study the power output of the array increases with 
increasing turbulence intensity. (0ther two-level arrays could perhaps be designed so the power output decreases with turbulence intensity.)

To investigate the sensitivity of these results to the turbine layout, the original layout ( $A$ ) was modified. Two more layouts, $B$ and $C$, are considered. Figure 6 shows layout B. In this figure, a column of the taller turbines is placed $40 \mathrm{ft}$ to the west of every second column of the shorter turbines.

Layout C, shown in Figure 7, was recommended by one of the reviewers of this report. He suggested that the tall towers used to support the upper level of turbines could be constructed as guyed towers (towers supported by guy wires) to reduce their cost. Guyed towers cannot be located close to the lower level of turbines since the blades of these turbines would hit the guy wires.

The results for these two layouts ( $B$ and $C$ ) are not very different than those obtained using the original layout $(A)$. Layout $B$ gives slightly worse results than $A$, while layout $C$ gives slightly better results.

Only the power loss (per turbine) for layout $C$ will be shown. Figure 8 shows this loss for a wind direction of $270^{\circ}$. The power loss is slightly less than the loss for layout $A$ for any given level of turbulence. For example, at a windspeed of about $38 \mathrm{mph}$, there is only a difference of about $2 \mathrm{~kW}$ for a transverse turbulence intensity of $12 \%$. 


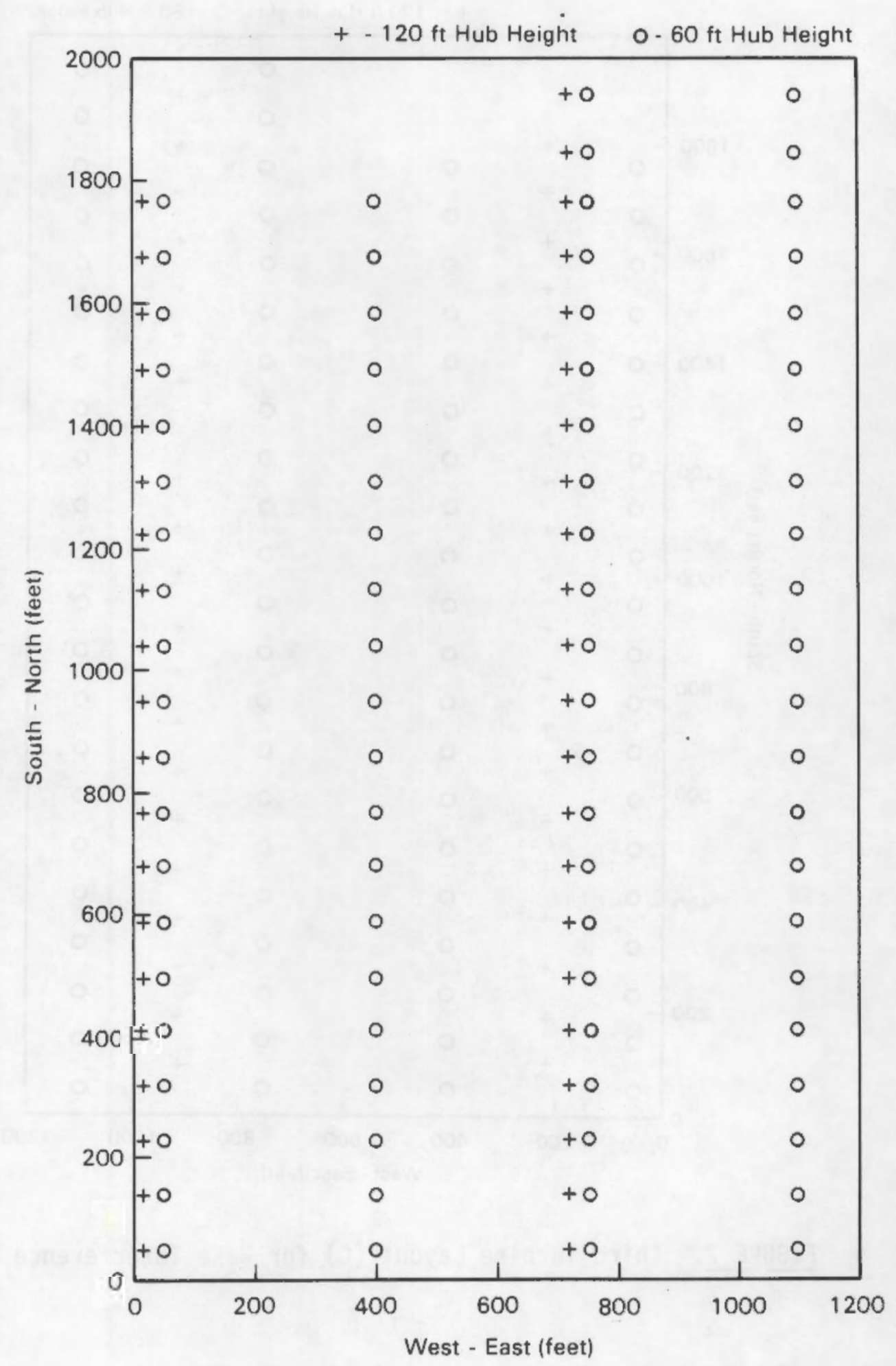

FIGURE 6. Second Turbine Layout (B) for Wake Interference Test. 


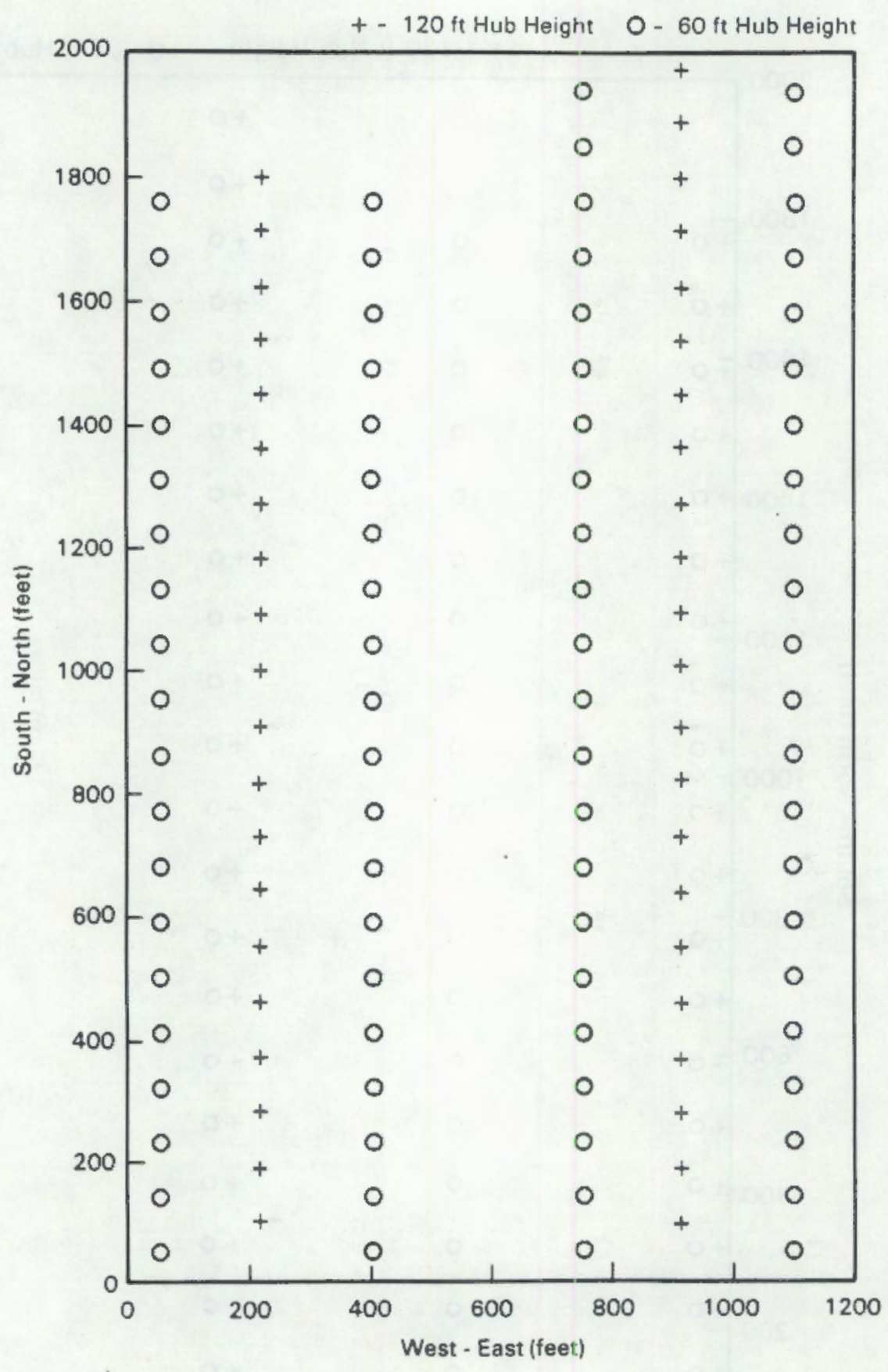

FIGURE 7. Third Turbine Layout (C) for Wake Interference Test 


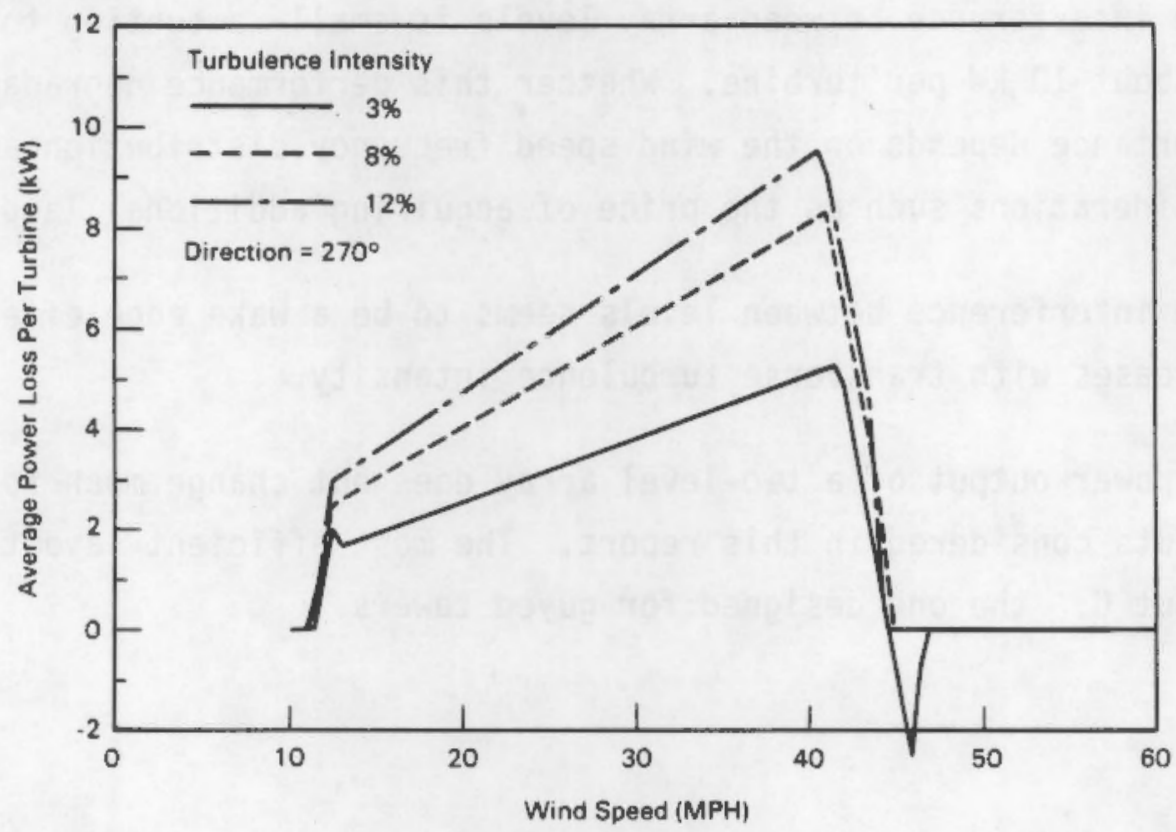

FIGURE 8. Power Loss (per turbine) as a Function of Wind Speed (Layout C) 


\subsection{CONCLUSIONS}

The conclusions drawn from this study are:

1. If the Lissaman array model can be believed, these results show that wake interference between array levels is small--amounting to a maximum of about $10 \mathrm{~kW}$ per turbine. Whether this performance degradation is of importance depends on the wind speed frequency distribution and economic considerations such as the price of acquiring additional land.

2. Wake interference between levels seems to be a wake edge effect and increases with transverse turbulence intensity.

3. The power output of a two-level array does not change much for the three layouts considered in this report. The most efficient layout is layout C: the one designed for guyed towers. 


\subsection{REFERENCE}

Lissaman, P.B.S., G. W. Gyatt, and A. D. Zalay. 1982. Numierical Modeling Sensitivity Analysis of the Performance of Wind Turbine Arrays, PNL-4183, Pacific Northwest Laboratory, Richland, Washington. 



\section{DISTRIBUTION}

No. of

Copies

OFFSITE

Carl Aspliden

Battelle Memorial Institute Washington Office

2030 M Street NW

Washington, OC 20036

J. Cadogan

Department of Energy

Wind Energy Technology Division

1000 Independence Avenue

Forrestal Building, Room $5 \mathrm{H048}$

Washington, DC 20585

D. F. Ancona

Department of Energy

Wind Energy Technology Division

1000 Independence Avenue

Forrestal Building, Room $5 \mathrm{HO48}$

Washington, DC 20585

G. P. Tennyson

Department of Energy

Albuquerque Operations Office

P.0. Box 5400

Albuquerque, NM 87110

P. B. S. Lissaman

Aerovironment, Inc.

$825 \mathrm{~S}$. Myrtle Avenue

Monrovia, CA 91016-3424

A. S. Mikhai]

InternationaT Dynergy, Inc.

777 E. Tahquitz-McCallum Way

Suite 333

Palm Springs, CA 92262

DOE Technical Information Center
No. of

Copies

ONSITE

DOE Richland Cperations Cffice

K. W. Bracken/D. R. Segna

34 Pacific Northwest Laboratory

J. C. Barnard (5)

J. H. Buck

J. R. ConneT?

D. W. Dragnich

C. E. Elderkin

D. L. Elliott

P. C. Hays

M. E. Hinchee

B. D. Holst

A. H. Mitier

V. R. Morris

E. L. Owczarski

D. C. Powell

J. A. Stottlemyre

T. K. Thompson

R. E. Wildung

H. L. Wegley

L. L. WendelT

Technical Information Files (5)

Publishing Coordination (2)

WCPE Program Office (5) 
